\title{
Cytotoxicity Evaluation of New Resin Matrix System on Fiber- Reinforced Composites
}

S SUNARINTYAS ${ }^{* 1}$, W SISWOMIHARDJO $^{1}$, HARSINI $^{1}$, JP MATINLINNA ${ }^{2}$

${ }^{1}$ Gadjah Mada University, Indonesia, ${ }^{2}$ University of Hong Kong, Hong Kong

\begin{abstract}
Objectives: Recent commercial resin matrix systems use bis-GMA as the basic matrix. Previous study showed bis-GMA affected the vitality of dental pulp and induced pulpal inflammation (Engelmann et al., 2004), was able to disturb normal differentiation procedures of pulp fibroblasts (Imazato et al., 2009), and induced allergic contact stomatitis (Stoeva et al., 2008). Alternative monomer for bis-GMA, such as 1,6 Hexanediol dimethacrylate (HDMA), is under our current research. The purpose of this study was to determine the cytotoxicity property of HDMA of E-glass FRCs on fibroblast cells by MTT method. Materials and Methods: The materials used were bis-GMA (Sigma-Aldrich, USA), MMA (ProSciTech, Australia), HDMA (Esstech, USA), CQ (Esstech, USA),CEMA (Esstech, USA), E-glass fibers (Stick Tech, Finland), Vero fibroblast cell line (UGM, Indonesia). Fifteen specimens of FRCs $(2 \times 2 \times 25) \mathrm{mm}$ were prepared and divided into 3 groups. The experiment groups were 78.4\%HDMA+ $19.6 \% \mathrm{MMA}+1.0 \% \mathrm{CQ}+1.0 \% \mathrm{CEMA}$ (Exp-1group) and 49.0\%HDMA+49.0\%MMA+ $1.0 \% \mathrm{CQ}+1 \% \mathrm{CEMA}$ (Exp-2 group) whilst the control-group was $78.4 \%$ bis-GMA+ 19.6\%MMA+1.0\%CQ+1.0\%CEMA. Specimens were milled and diluted in culture medium ( $0.1 \mathrm{mg}$ powder $/ 1 \mathrm{~mL}$ medium). Specimen solution of $100 \mu \mathrm{L}$ was added into 96-well plate containing fibroblast cells of $2 \times 10^{4}$ cells $/ 100 \mu \mathrm{L}$ and incubated for 24 hours. MTT of $10 \mu \mathrm{L}$ was added to the well, incubated for 4 hours, then $100 \mu \mathrm{L}$ stop solution was added. The OD of the cells viability was determined by ELISA reader with a wavelength of $550 \mathrm{~nm}$. Cells viability were calculated in percentage and analyzed by ANOVA and LSD. Results: The average of fibroblast cells viability in percentage (\%) showed for the Exp 1-group was $67.73 \pm 0.71$, Exp 2-group was $66.78 \pm 0.20$, and Control-group was $64.36 \pm 1.63$. Analysis by one way ANOVA revealed significant difference of cells viability among the groups $(p<0.01)$. The LSD test showed significant difference between exp-1 group and control group; and also between exp-2 group and control group $(p<0.01)$; whilst no significant difference between exp-1 group and exp-2 group ( $p>0.05$ ). Conclusions: A resin matrix system based on HDMA-MMA (exp-1 group and exp-2 group) revealed significant difference of fibroblast cells viability with bis-GMA-MMA matrix system. The HDMA-MMA matrix system was less cytotoxic than bis-GMA-MMA matrix system.
\end{abstract}

Key words : cytotoxicity - resin matrix system - fiber-reinforced composites 


\section{Introduction}

There has been increased interest in fiber-reinforced composites (FRC) material in dentistry. Fiber-reinforced composites have been used in removable prosthodontics (Valittu,1997), fixed partial dentures (FPD) (Valittu, 1998), periodontal splints, and in orthodontic treatment as a retention splint (Friskopp and Blomlof, 1984). Fiber-reinforced composites consist of resin matrix reinforced by fibers which induce relatively high strength and modulus (Mallick, 2008).

Matrix has the of function binding fibers together, transferring loads to fibers in the vicinity of fiber break via fiber-matrix adhesion, and protecting fibers from the outside environment such as chemicals, moisture and mechanical attack. Matrix influences the compressive strength, interlaminar shear and in-plane shear properties, interaction between matrix and fiber, and processing and defects in the composite (Mallick, 2008).

The composition of resin matrix is chemically complex since it contains a great variety of different monomers and additives (Glurtsen et al., 1998). Previous studies reported that residual monomers, additives, or polymerization products were released from set of resin matrix into adjacent tissues and oral cavity (Ferracane and Condon, 1990; Ferracane, 1994). The initial release of free monomers occurred during the monomer-polymer conversion and long term released of leachable substances generated by erosion and degradation over time (Goldberg, 2008; Gupta et al., 2012). The release of components into surrounding tissue may cause an adverse local reaction or even systemic effects.

The bis-GMA-MMA combination as the resin matrix is widely used. The MMA was reported becoming allergen in denture base material especially for dental technician (Pfeiffer and Rosenbauer, 2004). The release of residual monomer of MMA was also said to be the primary cause of irritation to the mucous membrane (Urban et al., 2007). Bis-GMA (figure 1) was considered to be relatively more cytotoxic and allergenic than the other monomers studied (Schmalz and Arenholt-Bindlev, 2009). It was reported that bis-GMA became the most cytotoxic monomer among 35 dental resin composite monomers includes bis-GMA, GMA, HDDMA, BPA, CQ, TEGDMA, HEMA, MMA, etc. (Moharamzadeh et al., 2009). Previous study showed bis-GMA affected the vitality of dental pulp and induced pulpal inflammation (Engelmann et al., 2004), was able to disturb normal differentiation procedures of pulp fibroblasts (Imazato et al., 2009), and induced allergic contact stomatitis (Stoeva et al., 2008). In fact, recent commercial matrix systems use bis-GMA-MMA system as the basic matrix components. To reduce the harmfully effect of this matrix system, it is necessary to look for a new saver matrix system for human instead of bis-GMA-MMA.

Resin matrix of 1,6 hexanediol dimethacrylate (HDMA) has similar reactive groups to bis-GMA (figure 2). The HDMA has the properties of low viscosity, fast curing monomer with low volatility, hydrophobic backbone, and good solvency for use in free radical polymerizatio (Valittu and Sevelius, 2000). 


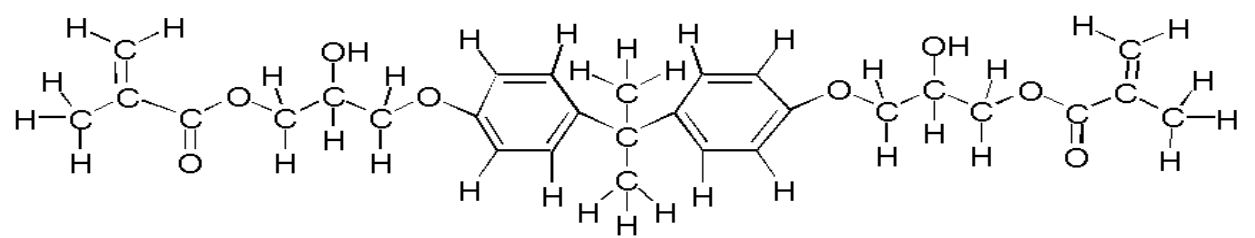

Figure 1. The structure of bis-phenol-A-glycidylmethacrylate (bis-GMA)<smiles>C=C(C)C(=O)OCCCCCCOC(=O)C(=C)C</smiles>

Figure 2. The structure of 1,6-Hexanediol dimethacrylate (HDMA)

The HDMA features water repellency property (hydrophobic). It is used as a functional monomer for polymers and as a cross linking agent between the molecular chains of polymers. Applications of HDMA include adhesives and sealants, coatings, elastomer, photopolymers electronics, improved adhesion, hardness, abrasion and heat resistance (Valittu, 2002). The toxicological properties of HDMA are reported not to produce mutagenic, embryo toxic, teratogenic, or reproductive effects in humans. Related to the carcinogenicity, it is reported that none of HDMA components are listed by IARC, NTP, OSHA, or ACGIH as carcinogens (Valittu and Sevelius, 2000).

The objective of this study was to determine the cytotoxicity property of HDMAMMA matrix system of E-glass FRCs on fibroblast cells by MTT method. Moreover, the cytotoxicity property of HDMA-MMA matrix system was compared to the bis-GMA-MMA matrix system.

\section{Materials and methods}

\section{Materials}

The materials used for the fiber-reinforced composites and their manufacturers are listed in Table 1. The vero fibroblast cell line was obtained from LPPT-UGM, Indonesia. The culture medium of RPMI 1640, Dulbecco's Modified Eagle's Minimum Essential medium (DMEM), penicillin, streptomycin, amphotericin, and trypsin were obtained from Gibco (Carlsbad, CA). All other chemicals were analytical or pharmaceutical grade and obtained from Sigma-Aldrich Chemicals (Bornem, Belgium).

The E glass fibers (R338-2400/V/P) were already silanized by the manufacturer and kept in desiccators for 24 hours prior to specimen preparation. The fibers were sized by immersion in a sizing solution $(50 \%$ wt $\%$ bis-GMA $+50 \%$ wt $\%$ MMA for the control group; $50 \%$ wt $\%$ HDMA + 50\% wt\% MMA for the Exp groups) for 1 minute. The sized fibers were cut into $25 \mathrm{~mm}$ long with a surgical steel knife for the preparation of test specimens (Matinlinna et al., 2009). 
Table 1. Materials used

\begin{tabular}{lc}
\hline Material & Manufacturer \\
\hline Bis-phenol-A-diglycidylmethacrylate (bis-GMA) & Sigma-Aldrich, USA \\
Methylmethacrylate (MMA) & ProSciTech, Australia \\
1,6-Hexanediol dimethacrylate (HDMA) & Esstech, USA \\
Camphorquinone (CQ) & Esstech, USA \\
N,N-cyanoethyl methylaniline (CEMA) & Esstech, USA \\
Unidirectional E-glass fibers & Stick Tech Ltd, Turku, Finland \\
\hline
\end{tabular}

\section{Specimen Preparation}

Two bundles of $25 \mathrm{~mm}$ long fibers reinforcement were placed along the long axis of the specimen into the mould and embedded into the resin matrix with different compositions as shown in table 2. Each group of matrix composition consisted of 5 specimens. Totally fifteen specimens with the dimension of $(2 \times 2 \times 25) \mathrm{mm}$ (Zhang and Matinlinna, 2011) were prepared. All specimens were light-cured on both sides with a light curing unit (Woodpecker, USA) for $3 \times 40 \mathrm{sec}$. After light curing, specimens were milled. The powder then diluted in culture medium $(0.1 \mathrm{mg}$ powder $/ 1 \mathrm{~mL}$ medium).

Table 2. Matrix composition (in wt\%)

\begin{tabular}{llllll}
\hline Group & Component & & & & \\
\cline { 2 - 6 } & Bis-GMA & MMA & HDMA & CQ & CEMA \\
\hline Control & 78.4 & 19.6 & 0 & 1.0 & 1.0 \\
Exp-1 & 0 & 19.6 & 78.4 & 1.0 & 1.0 \\
Exp-2 & 0 & 49.0 & 49.0 & 1.0 & 1.0 \\
\hline
\end{tabular}

\section{Cytotoxicity Evaluation}

The cytotoxicity evaluation by MTT method was based on ISO 10993-5 Part 5 (2009). Specimen solution of $100 \mu \mathrm{L}$ was added into 96-well plate containing fibroblast cells of $2 \times 10^{4}$ cells $/ 100 \mu \mathrm{L}$ and incubated for 24 hours. MTT of $10 \mu \mathrm{L}$ was added to the well, incubated for 4 hours, then $100 \mu \mathrm{L}$ stop solution was added. The OD of the cells viability was determined by ELISA reader with a wavelength of $550 \mathrm{~nm}$. Cells viability were expressed as the \% cytoviability, using the following formula :

$$
\% \text { cytoviability }=\frac{100 \% \times \mathrm{OD}_{550 \text { treated }}}{\mathrm{OD}_{550 \text { control }}}
$$

Where :

$\mathrm{OD}_{550 \text { treated }}$ : mean value of the measured optical density of the treated cells

$\mathrm{OD}_{550 \text { control }}$ : mean value of the measured optical density of the control cells 
The data were presented as means \pm standard deviation (s.d.) of cell viability.

\section{Statistical analysis}

The data on cytotoxicity property of bis-GMA-MMA matrix system and HDMA-MMA matrix system were analyzed by SPSS release 17.0 software. The level of statistical significant $(p)$ was set as 0.05 . The data normality was examined by KolmogorovSmirnov test. One way analysis of variance (ANOVA) followed by Post hoc least significant different (LSD) test were carried out.

\section{Results}

Table 3 showed the mean values of fibroblast cells viability in percentage (\%) for the FRC materials with different matrix composition groups. Each composition was evaluated for cytotoxicity of 5 replication samples.

Table 3. Average of fibroblast cells viability in percentage (\%)

\begin{tabular}{ll}
\hline Matrix composition & Percentage of cells viability (mean \pm s.d.) \\
\hline Exp 1-group & $67.73 \pm 0.71$ \\
Exp 2- group & $66.78 \pm 0.20$ \\
Control-group & $64.36 \pm 1.63$ \\
\hline
\end{tabular}

Table 3 showed the exp1-group had the highest value of fibroblast cells viability percentage while the control group had the lowest value. The viability value of exp1group and the exp-2 group were nearly similar. The data normality test proved all of the 3 group matrix composition had significant value more than 0.05 ; therefore it was concluded that the data had normal distribution and could be analyzed further by ANOVA. Analysis by one way ANOVA (table 4) revealed significant difference of cells viability percentage among the groups $(p<0.01)$. The LSD test (table 5) showed significant difference between exp-1 group and control group; and also between exp-2 group and control group $(p<0.01)$. There was no significant difference between exp-1 group and exp-2 group $(\mathrm{p}>0.05)$.

Table 4. One way ANOVA

\begin{tabular}{lccccc}
\hline & Sum of Squares & Df & Mean Square & $F$ & Sig. \\
\hline Between Groups & 30.164 & 2 & 15.082 & 14.149 & 0.001 \\
Within Groups & 12.791 & 12 & 1.066 & & \\
Total & 42.956 & 14 & & & \\
\hline
\end{tabular}


Table 5. Post hoc least significant different (LSD)

\begin{tabular}{llccc}
\hline$(\mathrm{I})$ & $(\mathrm{J})$ & Mean Difference $(\mathrm{I}-\mathrm{J})$ & Std. Error & Sig. \\
\hline 1.00 & 2.00 & 0.94800 & 0.65298 & 0.172 \\
& 3.00 & $3.36800^{*}$ & 0.65298 & 0.000 \\
\hline 2.00 & 1.00 & -0.94800 & 0.65298 & 0.172 \\
& 3.00 & $2.42000^{*}$ & 0.65298 & 0.003 \\
\hline 3.00 & 1.00 & $-3.36800^{*}$ & 0.65298 & 0.000 \\
& 2.00 & $-2.42000^{*}$ & 0.65298 & 0.003 \\
\hline
\end{tabular}

${ }^{\star}$. The mean difference is significant at the 0.05 level.

\section{Discussion}

Fiber-reinforced composite is a composite material made of a polymeric matrix which is reinforced by fibers. There are two types of polymer used in FRC, the cross-linked and linear polymers. The cross linking polymer refers to the multifunctional dimethacrylate resin. The linear polymer refers to the monofunctional methacrylate polymer (Mallick, 2008). In FRC with the IPN (inter penetrating network) structure, usually the matrix consists of a cross linking polymer, a linear polymer, and a photo initiator (Vallitu, 2009).

There are two kinds of setting reaction on FRC resin matrix, e.g. the polymerization reaction and the cross linking reaction. Polymerization reaction refers to the formation of a polymer by sequential adhesion of monomer units. The cross linking reaction in a polymer is the formation of a cross link where chains are bonded together either through direct connection or via an intermediary atom, ion, molecule or chain. This produces a three dimensional strongly cross linked system (Darvell, 2006).

The aim of this study was to determine the cytotoxicity property of HDMA based matrix system of FRC on fibroblast cells. Cytotoxicity as a primary factor of biocompatibility is generally determined by in vitro cell culture. In comparison with in vivo investigations, these in vitro studies are more easily controlled. In vitro methods permit assessment of various parameters in a simplified system, while minimizing variables and allowing more-specific determination of cytotoxic mechanisms. Although in vitro results cannot be quantitatively correlated with in vivo results, several clinical reports have demonstrated tissue cytotoxicity when tissue is exposed to component released from the curing resins (Barron et al., 1993). Oral tissue in direct contact with in situ polymerized resin may suffer higher concentrations of chemicals that will lead to greater tissue damage.

The current research aimed to replace the matrix of bis-GMA to HDMA in an FRC material. Bis-GMA has the advantage of low volatility and diffusivity into tissue and the formation of high moduli polymer with little volume contraction (Antonucci and Stansburry, 1997). These desirable properties of bis-GMA are partially negated by its relatively high viscosity and low vinyl conversion under ambient polymerization conditions (Khatri et al., 2003). To overcome these deficiencies a less viscous monomer is needed as a diluents comonomer such as TEGDMA, UEDMA, or replace the bis- 
GMA based matrix system. Moreover, the hydroxyl groups of bis-GMA are the major source of not only the high viscosity of the monomer but also contribute significantly to the relative high water sorption of bis-GMA based matrix. Excessive water absorption can have adverse effects on the properties of FRC by plasticization of the matrix by water and also by promoting possible hydrolytic degradative reactions (Khatri et al., 2003; Sunarintyas, 2012). The release of degradative components into the surrounding tissue may cause an adverse reaction.

Table 3 showed the exp1-group had the highest value of fibroblast cells viability percentage while the control group had the lowest one. The viability value of exp1-group and the exp-2 group were nearly similar. The exp-1 group and the exp-2 group had the matrix system of HDMA-MMA. By the data it was proved that the HDMA-MMA matrix system showed less cytotoxic effect on fibroblast cells. Structurally, the HDMA monomer had reactive groups similar to bis-GMA monomer and became good solvency for used in free radical polymerization. The HDMA configuration was linier without benzene groups as in bis-GMA. This condition contributed to the less viscosity property of HDMA than bis-GMA. Moreover, HDMA did not possess the hydroxyl groups as in bis-GMA which significantly affected the relative high water sorption. By this fact, it was assumed that the matrix system based on HDMA-MMA contributed less plasticization by water and hydrolytic degradative reactions. This condition affected the leachable component of matrix resin to the surrounding tissue and as a result there would be the better cytotoxicity property of HDMA-MMA matrix system than bis-GMA-MMA matrix system to the fibroblast cells. This phenomenon was linier as Yoshii (1997) found in the study of relationship of monomer structures and cytotoxicity which concluded hydroxyl groups on acrylates and methacrylates seemed to enhance cytotoxity. The exp-1 group had the highest value of fibroblast cells viability percentage might be caused by the more HDMA percentage content than the MMA in the matrix composition. The HDMA was reported less cytotoxic than MMA (Moharamzadeh et al., 2009).

Analysis by one way ANOVA (table 4) revealed significant difference of cells viability percentage among the groups $(p<0.01)$. The HDMA-MMA matrix system (exp-1 group and exp-2 group) and the bis-GMA-MMA matrix system had difference chemical matrix composition (wt \%). The difference in chemical composition might affect the cell viability. Al Hisayat et al. (2005) reported the change in the chemical structure of composite and variation in the ratio of filler and monomer significantly affected the element release and cytotoxicity level of the materials.

The LSD test (table 5) showed significant difference between exp-1 group and control group; and also between exp-2 group and control group $(p<0.01)$. There was no significant difference between exp-1 group and exp-2 group ( $p>0.05)$. By the LSD analysis it was seen that the HDMA-MMA matrix system was significantly higher influencing cell viability than bis-GMA-MMA matrix system. The percentage of HDMA composition in HDMA-MMA matrix system was not significantly influence the cell viability although it was determined the exp-1 group showed higher cell viability than the exp-2 group. By the fact that the handling property of the matrix system of exp-1 group was easier and more convenient than the exp-2 group (because of the better viscosity), and previous research of better mechanical strength of exp-1 group than exp-2 groups (Sunarintyas et al., 2012) and also higher flexural and hardness properties of the exp-1 group than the exp-2 group after 4 weeks water immersion (Siswomihardjo et al., 
2012); therefore it was recommended the exp-1 group to be evaluate further for the replacement alternative of bis-GMA matrix system.

\section{Conclusion}

This study demonstrated that a resin matrix system based on HDMA-MMA (exp-1 group and exp-2 group) revealed significant difference of fibroblast cells viability with bis-GMAMMA matrix system. The HDMA-MMA matrix system was less cytotoxic than bis-GMAMMA matrix system.

\section{References}

Al Hisayat AS, Darmani H, Milhem MM, 2005. Cytotoxicity evaluation of dental resin composites and their flowable derivates. Clin Oral Invest, 9: 21-5.

Antonucci JM, Stansbury JW, 1997. Molecularly designed dental polymers. In: Ar Shady R, editor. Desk reference of functional polymers: synthesis and applications. American Chemical Society Publication, p. 719-38.

Barron DJ, Schuster GS, Caughman GB, Levebre CA, 1993. Biocompatibility of visible light-polymerized denture base resin. Int J Prosthodont, 6: 495-501.

Darvell BW, 2006. A glossary of Terms for Dental Materials Science. $9^{\text {th }}$ ed. Darvelll, Pokfulam.

Engelmann J, Janke V, Volk J, Leyhausen G, Neuhoff N, Schlegelberger B, Geurtsen W, 2004. Effects of bis GMA on glutathione metabolism and apoptosis in human gingival fibroblasts in vitro. Biomaterials, 25:4573-80.

Friskopp J, Blomlof L, 1984. Intermediate fiberglass splints. J Prosthet Dent, 84; 334-7.

Geurtsen W, Lehmann F, Sphal W, Leyhausen G, 1998. Cytotoxicity of 35 dental resin composite monomer/additives in permanent $3 \mathrm{~T} 3$ and three human primary fibroblasts cultures. J Biomed Mater Res, 41: 474-80.

Goldberg M, 2008. In vitro and in vivo studies on the toxicity of dental resin components. A Review. Clin Oral Investig, 12: 1-8.

Gupta SK, Saxena P, Pant VA, Pant AB, 2012. Release and toxicity of dental resin composite. A Review. Toxicol Int, 19 : 225-34.

Imazato S, Horikawa D, Nishida M, Ebisu S, 2009. Effects of monomers eluted from dental resin restoratives on osteoblast-like cells, Journal of Biomedical Materials Research Part B: Applied Biomaterials, Volume 88B, Issue 2, pages 378-86. 
ISO 10993-5, 2009. Biological evaluation of medical devices - Part 5,Test for In Vitro Cytotoxicity, pp. 24-8.

Khatri CA, Stansbury JW, Schultheisz CR, Antonucci JM, 2003. Synthesis, characterization and evaluation of urethane derivates of bis-GMA. Dental Materials, 19: 584-88.

Mallick PK, 2008. Fiber-reinforced composites: Materials, Manufacturing, and Design. 3 rd ed. CRC Press Boca Raton, FL.

Matinlinna JP, Dahl JE, Karlsson S, Lassila LV, Valittu PK, 2009. Silanes and Other Coupling Agents. Vol.5. VSP/Brill, Leiden, The Netherlands, pp. 107-121.

Moharamzadeh K, Brook IM, Van Noort R, 2009. Biocompatibility of Resin-Based Dental Materials. Material, 2: 514-548.

Pfeiffer P, Rosenbauer E, 2004. Residual methyl methacrylate monomer,water sorption, and water solubility of hypoallergenic denture base materials. J Prosthet Dent, 92: 72-78.

Schmalz G, Arenholt-Bindlev D, 2009. Biocompatibility of dental materials, Springer, New York.

Siswomihardjo W, Sunarintyas S, Martosudjijo W, Irnawati D, Zhang M, Matinlinna JP, 2012. Biomechanical Properties of A New Fiber-Reinforced Composite. Abstract Book 2012 PER/IADR Congress, Helsinki.

Stoeva I, Kisselova A, Zekova M, 2008. Allergic contact stomatitis from bisphenol-AGlycydilmethacrylate during application of composite restorations. A case report, $\mathrm{J}$ of IMAB- Annual proceeding (scientific papers) book 2, p 45-6.

Sunarintyas S, 2012. The effect of immersion time on flexural strength of E-glass fiber reinforced composite. Proceeding Book - The $7^{\text {th }}$ International Conference on Biomedical Engineering and Medica Applications (ICBEMA) BME-Days 2012 , p 31-34.

Sunarintyas S, Siswomihardjo W, Martosudjijo W, Irnawati D, Zhang M, Matinlinna JP, 2012. Effect of a new resin matrix system on fiber-reinforced composites. Abstract Book 2012 PER/IADR Congress, Helsinki.

Urban VM, Machado AL, Oliveira R, Vergani C E, Pavarina A, Cass QB, 2007. Residual monomers of reline acrylic resins. Dental Materials, 23 (3): 363-368.

Valittu PK, 1997. Glass fiber reinforcement in repaired acrylic resin removable dentures: preliminary results of a clinical study. Quintessence Int $28: 39-44$. 
Valittu PK, 1998. The effect of glass fiber reinforcement on the fracture resistance of a provisional fixed partial denture. J Prosthet Dent, 79:125-30.

Vallittu PK, Sevelius C, 2000. Resin bonded glass fiber reinforced composite fixed partial dentures: A clinical study. J Prosthet Dent, 84:413-418.

Vallittu PK, 2002. Strength and interfacial adhesion of FRC-tooth system. In Vallittu PK (ed). The Second International Symposium on Fibre-Reinforced Plastics in Dentistry. University of Turku, Institute of Dentistry and Biomaterials Research.

Vallitu PK, 2009. Interpenetrating polymer network (IPNs) in dental polymer and composites. In Matinlinna JP, Mittal KL (eds.) Adhesion Aspects in Dentistry. CRC Press, Bocaraton, p 63-74.

Yoshii E, 1997. Cytotoxic effects of acrylates and methacrylates: relationship of monomer structure and cytotoxicity. J Biomed Mater Res, 37: 517-24.

Zhang M, Matilnlinna JK, 2011. The effect of resin matrix composition on mechanical properties of E-glass fiber-reinforced composite for dental use. J of Adh Sci and Tech, 20: 1-11. 